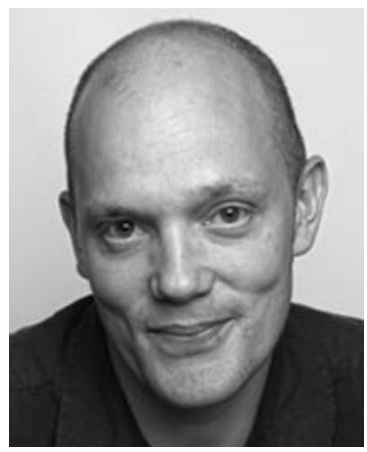

\title{
A Conversation with Matthew Rushworth
}

\author{
INTERVIEWER: JAN WITKOWSKI \\ Executive Director of the Banbury Center \\ at Cold Spring Harbor Laboratory
}

Matthew Rushworth is a Research Fellow in the Department of Experimental Psychology and Centre for Functional Magnetic Resonance Imaging of the Brain (FMRIB), University of Oxford.

Jan Witkowski: Tell us about your work in understanding decision-making and the brain mechanisms involved.

Dr. Rushworth: The sort of things I'm interested in are how we make decisions and the brain mechanisms that underlie our ability to make decisions. What we are doing is weighing up one option and considering its value, and comparing that with the value of some alternative course of action, and how we come to a resolution, a decision, about what's the best thing to do.

Jan Witkowski: So what sort of experimental tests do you do?

Dr. Rushworth: We're interested in every type of decision you might make. Perhaps you have a choice of two different wines to drink. And when you're confronted by that choice, what you're going to summon up is a memory of how good, say, that particular white wine and red wine were the last time you tried them. And then you make some comparison between your internal representation of the value of those two different things. And what I'm interested in is how that comparison process works. So when we conduct an experiment we give subjects really simple decisions to make, normally just between two different visual stimuli. And the subject makes the decision in order to win some points and we scan their brain using fMRI while they make that decision, and then we ask them to take a very similar type of decision again a few seconds later, and then again a few seconds later. And by repeatedly asking subjects to make 100 or so simple decisions, we're able to gradually average together the activity that is occurring each time a subject makes a choice.

Jan Witkowski: In this case, you're presenting them with just one alternative but you also add in a third possibility.

Dr. Rushworth: Yes. We think there's a particular part of the brain called the ventromedial prefrontal cortex that carries out a process of value comparison, comparing the value of Choice A with the value of Choice B. And even- tually a conclusion is reached about which one would be the better option to take. If we use fMRI to record activity in this brain region, we can see that the activity there is correlated with the difference in value between those two choices. And we think that the difference in value between the two choices is the key decision variable that defines how much better one thing is than the other. So the value difference is what drives our choice and the activity in this brain region covaries with that.

Jan Witkowski: And in the experimental setup, one choice is made more favorable than the other and more points are given for selecting that?

Dr. Rushworth: Sometimes one choice will have more points or a higher probability of points associated with it. And the subjects will have learnt about these contingencies before they come into the experiment. If we add into the mix a third option, we're interested in how this value comparison process gets subtly altered as there are more and more potential options to consider. And it turns out that the value comparison process becomes a bit more inaccurate when there are multiple alternatives.

Jan Witkowski: By "inaccurate" you mean that the subject more frequently chooses a lower value than the higher one?

Dr. Rushworth: Exactly. If, as in our experiments, there is an objectively better option and worse option, on occasions, when we add in a third option, the subjects can become a bit less accurate in choosing between the first two options. So if you were out buying groceries, and you wanted to buy a particular type of bread, and there were just two choices, your preferred option and your less preferred option, you're going to make that choice accurately. But the claim is that when you make that choice when there are multiple different varieties of bread available, somehow your comparison mechanism is confused by the multitude of options. So if you have more opportunities, more potential choices, you might end up being a little less satisfied with the choice that you made. 
Jan Witkowski: In the experimental setup, what's the relative value of the third option, the distractor?

Dr. Rushworth: The most distracting type of third option is one that is very low in value. And we think in a situation in which you have two good things to choose between, a very poor third alternative leads to more inaccurate choices.

Jan Witkowski: That seems rather counterintuitive. You'd have thought that if the distractor was higher in, closer in value to the A or B choice, you'd spend more time taking $\mathrm{C}$ into account.

Dr. Rushworth: Certainly as that third C option increases in value, you do become more likely to end up choosing it. But there's another type of error that you can look at, and that is inaccuracies in your choice between $A$ and B. So if A's better than B, then B is the worse choice, and the proportion of $B$ choices can suddenly, subtly increase when the $\mathrm{C}$ option value decreases. And the reason for this, we think, is because the comparison process is being mediated by an inhibition process. We can imagine two pools of neurons, one representing Choice $A$ and the other Choice B. And they're fighting against one another, so one pool of neurons is inhibiting the other. Ultimately only one of the pools of neurons ends up being active and the other one becomes inactive. It's the inhibition process that mediates this competition process. So A may end up active, or B may end up active, but the other option becomes inactive. The reason why a low-value third option has its effect is because it sends an excitatory influence into the inhibitory pool. If it's a poor-value third option, it doesn't add much to the inhibitory pool, and it's this inhibitory pool that mediates the decision process. So if there isn't much inhibition going on, then the comparison process between those two options doesn't work so effectively. That's the logic behind it.

Jan Witkowski: It sounds a bit like U.K. elections, where the Conservative and Labour parties have now been joined by the Liberal Democrats, who are not a very strong choice, but can spoil the success of one or other party.

Dr. Rushworth: Yes, although other analogies might be less politically contentious. But although there may be something counterintuitive about this process, there are also some situations in which it is a bit more intuitive. Imagine if you're a foraging animal and you don't have long to make a decision because there's a risk of losing the available options. In that situation you don't just want to make the right choice, but to make it quickly as well. So if you have two things together that are both very high in value, and you know there are other things in the environment that are terrible, it's quite a good choice, if not an optimal one, to choose either of those two good things.

Jan Witkowski: So what about the length of time an animal should forage in an increasingly poor environment, rather than risk moving off to what might be a better place?

Dr. Rushworth: That is another line of experimentation, where we're interested in how an animal, or a human in our investigations, has a sense of how well they've been doing recently. We think this is a different type of decision process that depends on different brain areas and different types of mechanisms. And the key idea here is that in some situations, there isn't really a choice between two different things. Instead there's a choice about whether or not to carry on doing something that you're already doing, or to switch to some perhaps more profitable behavior elsewhere. In order to guide this type of decision, we think you need to have an estimate of how well you've been doing recently, and some longer-term, average sense of how well you've been doing over time. And by comparing these two things you can work out whether it's worthwhile carrying on as you were or switching to something else.

Jan Witkowski: You must presume then, that part of this computation must be some estimate of how successful it was in the past to leave this point and risk going some distance away where things may or may not be better.

Dr. Rushworth: You're right that that's an important part of the process, the ability to learn this information, relate it to particular cues in the environment, and recognize those cues when you see them again, telling you that you're again in the same type of situation. But at the moment our investigations are at a slightly earlier stage, where we're just trying to see how it is that our human subjects are trying to estimate how well they're doing now and how well they've been doing over the longer term, and how they compare those two different estimates.

Jan Witkowski: You presumably are not looking at the postchoice period.

Dr. Rushworth: We do sometimes. There are some situations where it seems as if having made a particular choice, we become more likely to commit to that choice again in the future. So it seems as if some of the same brain mechanisms are maybe assessing the success of the choice that we have just made, in order to repeat it, or to switch to some alternative. We know that the same anterior cingulate brain regions that are mediating this second type of decision are evaluating the outcome of the choice, as well as being active before the choice is made.

Jan Witkowski: You're carrying out these experiments in a laboratory setting, or at least in a very carefully controlled setting. Can you devise real-world observational tests, looking at what people do when they're presented with a situation like whether or not to run for a bus or wait for the next.

Dr. Rushworth: Part of the art of designing experiments like that is to drain the decision-making problems of all of their color and interest and make them repetitive, in order to gather consistent data, time after time. And the reason for doing this is that our tools for measuring neural activity are relatively insensitive, so we have to average together activity recorded on multiple different occasions and multiple different simple decisions. But one way we 
can try to see if these measurements, these rather artificial types of scenario, relate to real-world behaviors is to give our subjects questionnaires about other types of decisions they might make. And then we can try to see if, say, a particular way of performing in our basic, simplistic experimental paradigms might relate to what they habitually do in the real world.

Jan Witkowski: When an individual C. elegans is moving along and makes a decision to change direction or go off in a similar direction, is there any relationship between the types of decision and the neural structure system that the $C$. elegans uses to make those sorts of decisions?

Dr. Rushworth: In C. elegans, you've got an animal with only 300 or so neurons, nevertheless there are some basic similarities between the models we use and the processes in worms, where neurons or pools of neurons are competing with one another in order to bring about a decision process. 


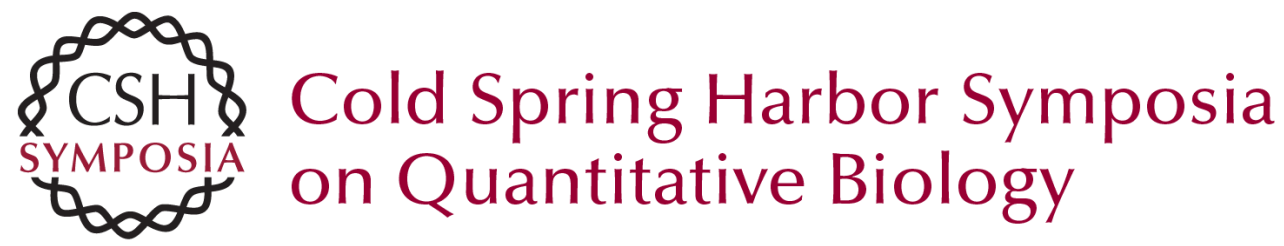

\section{A Conversation with Matthew Rushworth}

Cold Spring Harb Symp Quant Biol 2014 79: 288-290

Access the most recent version at doi:10.1101/sqb.2014.79.15

\section{License}

Email Alerting Receive free email alerts when new articles cite this article - sign up in Service the box at the top right corner of the article or click here. 